\title{
A LAW AND ECONOMICS ASPECTS OF THE IMPLEMENTATION OF SMART GRID IN THE RUSSIAN FEDERATION, PROBLEMS AND PERSPECTIVES OF THEIR USE
}

\author{
Strenin Danil ${ }^{1, *}$ and Maydibor Daria $^{2}$ \\ ${ }^{1}$ Financial University under the Government of the Russian Federation, Faculty of Law, 49 Leningradsky Prospekt, \\ 125993, Moscow, Russia \\ ${ }^{2}$ Financial University under the Government of the Russian Federation, Faculty of Economics and Business, 49 \\ Leningradsky Prospekt, 125993, Moscow, Russia
}

\begin{abstract}
In the course of this work, the authors considered the features and prospects of introducing smart energy systems in the Russian Federation, highlighted the legal problems that arise during the implementation of technologies, suggested possible solutions to them and made recommendations for the effective implementation of this activity.
\end{abstract}

The 21st century is the century of new technologies, the century of introducing innovations in all spheres of public life. Modern energy does not stand aside. One such innovation is Smart Grids. By Smart Grids we mean an automated set of algorithms that independently monitors and distributes electricity flows to achieve maximum energy efficiency, as well as other tasks.

The emergence of a new generation of Smart Grids is caused by the following reasons:

- distribution of generation, as well as an increase in the volume of technologies used based on renewable energy sources;

- $\quad$ the emergence of new methods of managing consumer services, innovative energy storage technologies;

- the discovery of new approaches in the field of energy supply and distribution during the use of highly intelligent automated systems;

- the advent of new applications working with data analytics on high-voltage networks.

The idea of smart energy systems is embodied in the form of a single set of devices that make it possible to achieve automation of the processes of activity of energy companies and utilities, as well as provide the ability to carry out high-quality monitoring and control of the two-way energy flow along the entire length of the production chain - from a power plant to the end consumer. Along with the two-way power transmission channels, the system has two-way data exchange channels that receive information from the object and transmit control commands to it.

This smart system uses sensors, counters, analytical tools and digital controls. The data from the sensors enter the information systems, which, analyzing the incoming information, are able to make decisions about whether to change the route of electricity flows, the mode of operation of household appliances or industrial installations in order to consume a valuable resource - electricity - as efficiently as possible and ultimately avoid energy collapses.
The introduction of Smart Grid in the energy sector provides optimization of productivity, prevention of downtime and quick recovery from power outages. For consumers, this transformation opens up the possibility of managing their own energy consumption at the level of individual electrical appliances connected to the network.

The evolution of Smart Grid technologies can be visualized and viewed in two stages. The first modernization - completed by 2015 , should include various equipment for transmission and measurement, examples of which are measuring instruments, transformers, capacitors and plugs, and partly automated control systems. The latter are at the junction of the described stages and are widely used in the transition to the second - a breakthrough through integration with information and communication technologies. Examples of these systems are SCADA and PMUs systems, voltage sensors, Demand Side Management, power distribution automation. Currently, an advanced measuring infrastructure in the form of smart meters, price-dependent consumption, energy management, and also the so-called microgrids: ultra-advanced current limiters, energy storage, smart devices, and power management platforms [1].

Transformation of the electric power industry segments allows achieving the following effects: increasing production capacities and providing power to remote and isolated regions, reducing losses arising in the process of transmission and transformation of electricity; reduction of peak network loads during power distribution and, as a result, reduction of operating costs and losses. In addition, the transformation of the segments will allow for accurate metering of consumption, and in the business environment to meet the growing requirements for environmental friendliness and energy efficiency of production, integrate electricity markets, introduce integrated intelligent management of both demand and consumption, as well as manage and supply to the 
market surplus energy, where former consumers will become producers of electricity.

Practical measures for the transition to the Smart Grid should become a necessary component of the entire technological process of renewing the electric power industry in Russia. So, replacing old equipment with a similar or technically progressive new one is not enough for the effective implementation of the transition - the primary task is to introduce it into the energy Internet, which will allow it to be embedded in the active part of innovative systems for managing economic interactions and technological processes, to apply it not only on the local, but also at the regional, federal and even national levels.

Implementation of the action plan for the implementation of smart measuring systems will allow achieving a number of socio-economic effects:

- changes in the export diversification index, GDP structure, as well as building up the export potential of the state through the formation of a sustainable export flow of software, equipment, smart energy systems services and integrated engineering services. The gross turnover of domestic enterprises in the markets of "target countries" is estimated by analysts at $\$ 40$ billion in 2035 [2];

- strengthening the positions of domestic companies in the international arena and the global energy market through the introduction of EnergyNet technologies; - potential reduction of technical losses by up to $50 \%$ through the installation of more high-tech metering devices and targeted network repair, the volume of required capacities - up to $80 \%$, operating costs - up to $10 \%$ due to a decrease in the number of employees and maintenance and repair volumes, a decrease in consumer debt by up to $30-50 \%$ due to timeliness of payment [3];

- achievement of a higher quality of power supply, development of household and industrial segments of the equipment energy efficiency market;

- development of the information technology industry, various areas of engineering in key areas, the formation of a talent pool in the field of high-tech industries, training of specialists with skills to work in global markets;

- savings on energy marketing activities arising from the introduction of new financial technologies that allow automating the settlement processes, resulting in a reduction in the cost of energy consumption.

However, smart grids cannot be implemented ignoring the world experience, both technological and organizational and economic. Table 1 highlights the main technologies of strategies for the implementation of smart grids in 4 leading countries in this direction.
Table 1 Characteristics of smart grid implementation strategies ${ }^{1}$

\begin{tabular}{|c|c|}
\hline Country & Key technologies used \\
\hline England & $\begin{array}{l}\text { 1. Implementation of smart } \\
\text { meters, creation of applications } \\
\text { for monitoring and control; } \\
\text { 2. Priority for the use of renewable } \\
\text { energy sources, gradual } \\
\text { integration into network } \\
\text { infrastructure systems; } \\
\text { 3. Regular diagnostics of power } \\
\text { supply voltage; } \\
\text { 4. Application of thermal energy } \\
\text { storage systems. }\end{array}$ \\
\hline India & 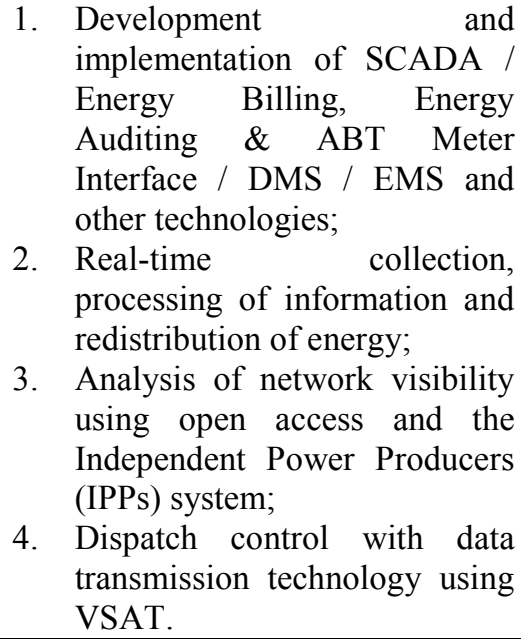 \\
\hline USA & $\begin{array}{l}\text { 1. Application of the Advanced } \\
\text { Power Distribution System } \\
\text { (DMS); } \\
\text { 2. Implementation of automated } \\
\text { switches at distribution centers; } \\
\text { 3. Launch of remote control and } \\
\text { monitoring of equipment at } \\
\text { substations; } \\
\text { 4. Installation of new components } \\
\text { to stabilize and raise the level of } \\
\text { the technical condition of the } \\
\text { network. }\end{array}$ \\
\hline $\begin{array}{l}\text { Sweden } \\
\text { (automation } \\
\text { of the smart } \\
\text { grid of the } \\
\text { seaport in } \\
\text { Stockholm) }\end{array}$ & $\begin{array}{l}\text { 1. Improvement of the Peak Load } \\
\text { Management (DSM) system; } \\
\text { 2. Widespread introduction of } \\
\text { RES; } \\
\text { 3. Electrification of the bay, ship } \\
\text { docks, docks; } \\
\text { 4. Automation of systems of } \\
\text { structures and buildings of port } \\
\text { services; } \\
\text { 5. Improving the quality and } \\
\text { efficiency of energy storage } \\
\text { systems. }\end{array}$ \\
\hline
\end{tabular}

It should be noted that today a significant part of smart grid technologies developed and successfully implemented abroad, in particular, in the West, cannot

${ }^{1}$ Compiled by the authors based on [1]. 
be applied in Russia and the CIS countries due to the significant differences in domestic and Western electric power infrastructures that have not yet been eliminated. That is why, taking into account the specifics of large domestic power grid complexes, in Russia at this stage of technological development, it is advisable to only partially introduce smart power systems, which are aimed at solving the key existing problems and tasks of the industry.

Russia has great potential for the development, implementation and use of smart energy technologies. Acceleration of the development of Smart Grid principles can be both borrowing an integrated approach used in the leading countries in the implementation of smart energy systems technologies, and international cooperation with them. All participants of the energy market will have to make efforts in a coordinated and coordinated way, as it is difficult to create a single intelligent power system, working in a different way. It was necessary to work together within the energy value chain, which should unite the interests of generators, distribution networks, marketing companies and consumers. The value chain assumes that new market players will have to share basic information with each other in real time, while at the same time enabling consumers to obtain key information on price conditions, loading modes, savings in time and other important parameters for engaging consumers in the optimization process of the entire grid. In this process, the State has an important role to play, which should take on the functions of coordination, support and incentives. In addition, in practice, the effectiveness of the creation at the government level of institutions responsible for the creation, development and use of technologies in the field of monitoring and accumulation of renewable energy, the development of mechanisms for attracting both public and private investments, the launch of various educational programs in this area for the population, support and financing of projects has been proven.

Smart grids can include new renewable energy sources, such as wind turbines and solar panels. They can also be used locally with distributed energy sources or network-connected electric vehicles. All of these elements of a single system are managed by the necessary software-but-hardware tools, such as a highperformance computing system that allows real-time information to be processed, streaming tools that allow it not to store vast amounts of incoming information, but to filter it, process it in a necessary way and make management decisions. Another important aspect that is not being given sufficient attention is ensuring the security of the "reasonable" power grid that we are striving to build. The more data, data and information, the greater the threat of external intruders to have a negative impact on the grid. Therefore, we can expect an increase in investments in providing integrated (at the junction of physical and digital networks) security.

The potential effects of the large-scale application of smart grids in Russia include an increase in the competitiveness of the domestic energy-intensive industry, which will make up the main share in the national economy for at least 15 years [3]. In addition, the implementation of reliable, flexible networks will lead to increased efficiency in the use of today's infrastructure. It is expected that investment needs over the next 5 years will decrease to $30 \%$ [1], while the savings will be redistributed and directed to the further development of technologies.

In addition, smart power systems can be considered as an important tool in the implementation of the Energy Strategy of the Russian Federation until 2035, in particular, its priorities. Among the key authors identified the following areas:

- reduction and minimization of the negative impact on public health and the environment;

- increasing the efficiency and rationality of using the potential of the fuel and energy complex;

- supporting and ensuring the development of competition, transparent pricing mechanisms in the energy market;

- increasing and ensuring the energy and information security of individual regions and the entire state as a whole.

It is worth noting that in Russia the smart grid market is just emerging, so in domestic practice there are not so many examples of their implementation. The experience of implementing Smart Grid in such cities and regions of Russia as Ufa, Sergiev Posad, Kaliningrad Region, and the Republic of Bashkortostan can be called successful.

The transition to Russia's Smart Grid will help to restrain the growth of electricity prices until 2035 by increasing generating and network capacity, quantitatively reducing energy losses to $70-80 \%$ and reducing the need for new capacity to $60-70 \%$ [1]. In addition, the above will significantly reduce the accident rate in the engineering infrastructure, improve the level of energy security and quality of life of the population as a whole.

However, the introduction of intelligent power systems in Russia is complicated by some legal problems. Let's take a closer look at them.

As we know from historical experience, any positive economic changes associated with the automation of production have negative consequences for some categories of citizens. In the case of the widespread use of intelligent power grids, there will be a reduction in the number of employees who, up to a certain point, have performed the working functions of the intellectual power grid. The termination of the employment contract in this case will take place on the basis of section 2 of Article 81 of the Russian Labor Code [4].

Since the widespread introduction of smart power grids is expected, we believe that a large number of employees in this industry will acquire the category of unemployed. In this regard, we propose the adoption of a federal law obliging the employer in the case of the introduction of automated systems in the energy sector of the economy six months before the planned reduction to provide an opportunity at the expense of the organization to take specialized courses of shift profession to employees who fall under the reduction or pay a premium of n-number of monthly salaries. 
These proposals allow observing the norms of Article 75 of the Constitution, taking into account the amendments made to it [5].

This problem is acute not only for the energy sector, but also for all sectors of the economy subject to digitalization and robotization. In this case, the presence of a special federal law will protect the legal rights of citizens and reduce the further growth of poverty and unemployment[6].

It may seem that another way to solve this problem is to introduce an additional tax on the use of weak artificial intelligence in various types of production and the redistribution of funds to citizens who need them. A similar initiative was announced by the Institute of Progressive Education on July 24, 2020. However, such actions will ultimately lead not to an improvement in the life of the population, but to a slowdown in the growth of technological development of the entire robotics industry and the use of artificial intelligence systems.

The reason for this will be the fact that the mentioned industry at this stage of its existence is just emerging, despite all the successes achieved. A nascent industry always requires large and long-term public and private investment, which in turn means that each cash flow will directly affect the pace of development. And now let's say that under such conditions, this branch of the economy, the industry for which the future will be subject to a constant tax burden from the state, redistributes $13-15 \%$ of its potential income not to improve production technology or improve the quality or quantity of potential tests of its products, but to pay taxes[7]. Of course, taxes are important for the state, but this instrument should be used with extreme caution[8].

It would be optimal to subject this industry to minimal taxation only when it becomes, firstly, more significant in terms of GDP formation and, secondly, much more profitable than it is now[9].

Another problem that arises during the digitalization of public life is the rather high probability of a technical failure of the program. Even a minor programmer error in the code can lead to the collapse of the energy system. To prevent this from happening, it is necessary to give the weak artificial intelligence, on the basis of which the smart grid functions, the possibility of practice in real life, allowing to identify such errors and correct them. Thus, we came to the first paradox of a real error artificial intelligence will make mistakes in the real world, which can have extremely negative consequences, but in order to avoid such consequences, it must make mistakes as many times as possible in order to be able to foresee its possible mistakes in the future.

The best way to solve this problem without harmful consequences would be to use virtual space to test weak artificial intelligence. Artificial intelligence in this case will not be able to harm the real budget system, but only that which has no physical embodiment in the ordinary world. However, for the problem to be solved, it is necessary to complicate the virtual space with all the variety of existing social relations, which is the next problem - the lack of necessary technologies in the world.

Today we cannot, without distorting, completely "digitize" the world around us, with all its social subjects, since the behavior of one particular person or any natural phenomenon depends on an infinite number of factors, most of which cannot be described in the language of mathematical models on which it is built the virtual reality.

The only way to solve this problem is to use "limited weak artificial intelligence". In this case, the problem of digitizing the whole world for testing it does not arise, we can limit the scope of its application, thereby simplifying the reality in which it should exist, which in turn will cause simplification to the possible limits of the virtual space in which it should pass tests. This means that there is no need to test in the real world, which in turn protects it.

At present, there are many ways to test weak artificial intelligence and its simulation. This largely depends on the application of low AI. Therefore, voice assistant is not tested separately in virtual space, but is put into our life immediately.

This makes sense, because their actions may pose the least danger to society, and in order to function better, they must "talk to as many people as possible.". The key factor in testing low AI in daily life is the initial restrictions imposed by developers.

For example, a voice assistant "Alice" can't insult you. This option and the corresponding vocabulary set don't exist in her software or so-called "core.". Alice uses two modes of communication - polite intonation and jokes. We draw attention to this seemingly insignificant fact, as it shows one of the avenues for the development of all legal science in the future.

When the two subjects come into contact in daily life, their way of communication is not strictly restricted by the law. Only when they are absolutely necessary can they communicate as they think necessary. But it should not infringe on each other's rights. The law also does not specify the language an entity can use or not use in private conversations. But when we talk about a person talking to a voice assistant, the main moderator is not the law of the Russian speaking country, A user agreement between an individual and a company that owns the technology.

Yes, of course, the agreement is based on the legal system of the host country, but it contains more restrictions, If a person wants to take advantage of the company's technology, he must abide by the user agreement.

By analogy, smart energy systems must also be considered. If they're private companies, The limits and rules of their activities should be determined in advance at the legislative level, in close cooperation with the relevant professionals, How they have to work. Such restrictions will help protect humans from possible errors in artificial intelligence. In addition, the introduction itself must be carried out step by step, so that people can adapt to the new energy reality and make artificial intelligence think Consistency in all cases. At the same time, the gradual adoption of this technology can also avoid fatal errors - if the program 
fails, it will not be completely destroyed and rewritten, But only two steps back can theoretically save enough resources. However, if there are dangerous consequences of society and mistakes have occurred, what should we do?

The next significant problem is the legal responsibility of the corporation and individual individuals for the operation of the automated power system. In modern domestic law, there is no mechanism for bringing a virtual program to justice. However, we are considering such a system, which, as we said earlier, is a limited weak artificial intelligence, which means there is no volitional criterion for perceiving existing reality, and in the absence of a person's will, it cannot be a subject of an offense..

Let's suppose that the actions of the power system led to an environmental disaster. In this case, it will be necessary to identify the reasons for such actions. There may be several of them - an error in the software of an intelligent energy system, unfair actions of an energy company or individual individuals.

In the first case, the specific programmer or the company that released the program will bear legal responsibility. An energy enterprise in such circumstances will not be liable, but if there is negligence in its actions, we assume the possibility of bringing the enterprise itself to responsibility [6].

In the second situation, the company whose actions or omissions caused damage to the environment will be directly held liable. Similarly, with case 3 , a certain person will be held accountable, in whose actions there is guilt.

But what if the actions of the programmers, the energy company, and specific individuals were correct, and the reason for the disaster was the decision of the intelligent energy system itself? What if the program considered a disaster to be more preferable than, say, the likely loss of a utility? Such an example cannot be regulated by modern law, and, of course, any actions that cause harm must be stopped and must bear consequences. In such a confluence of circumstances, we propose to use the analogy of law and use the concept of joint legal liability existing in the current legislation.

By this analogy, both the author of the program and the enterprise itself should be subject to responsibility, and the novelty will be the fact that that between these subjects there was initially no conspiracy to commit an offense, their guilt is relative, but their joint actions led to the onset of negative consequences. It will also be necessary to change the program that made the error. It will also be permissible to expand the subject of the offense to the owner of patent rights for the intellectual energy system program in the event that the enterprise or the direct author of the program does not have such rights, since before the direct use of his patent for a monetary remuneration, he had to make sure of its safety.

Above, we described the theoretical concept of legal liability for an error in an intelligent power system. Let's consider the problem from a practical point of view.
The system of tripartite legal liability developed by us can be applied in the framework of civil law relations in order to determine the subject, obliged to compensate for the harm caused indirectly by his actions. In this case, the civil liability of the three parties indicated above will be subsidiary in nature, and the main obligated person will be the enterprise itself.

From the standpoint of criminal law, the subject of a crime cannot be a legal entity, which means that it is possible to bring to criminal responsibility specific individuals, and not the enterprise itself. These individuals should include those who are responsible for testing the smart grid and running it. The subjective side of the crime will be expressed in criminal negligence or in criminal negligence in all cases when the intentions of the perpetrators were not aimed at the direct fact of committing an environmental crime. If intentions were nevertheless directed, the subjective side will be expressed in direct intention. The object of the crime in each case will be different, but the most likely object will be public relations arising in the field of ecology and the environment.

In administrative law, legal entities can act as the subject of an offense, which makes it possible to bring the energy company itself to justice. The key in this case will be the proof of the fact of the connection between the intelligent energy system and the energy corporation.

Russian legislation allows several types of liability to be applied to the offender at the same time. In the situation we are considering, legal responsibility in the event of an error in the smart power system that led to negative consequences will be distributed as follows:

- the owner of the patent for the smart power system, its author and the enterprise using this system will be brought to civil liability;

- the enterprise that made a mistake in the intelligent power system will be brought to administrative responsibility;

- specific individuals who had the duty to control the testing of the program and are responsible for its use will be brought to criminal responsibility.

The fact of an error in the smart grid program will cause the utility to shut down for a while.

This fact can negatively affect public well-being in view of the importance of the energy industry for socio-economic relations. This can be avoided by the presence of either a certain number of reserve personnel, or the use of another intelligent system. The second option is preferable in our case. The key in this matter is the fact that it must not be the system that made the mistake. Therefore, the energy company needs to develop 2 systems in parallel: one main and one additional, and if the first makes a serious mistake, it should stop, and the emergency one should start working.

Thus, in the course of this scientific work, we analyzed the ways to solve the problem in other states, considered the prospects for the introduction of intelligent energy systems in Russia and proposed ways to solve some legal and technical incidents associated with this implementation. 


\section{References}

1. Report of the Foundation for Strategic Research "North-West". Technologies for smart cities. Center for Strategic Research North-West Foundation. $2017.110 \mathrm{~s}$;

\section{Mikheev E.A., N.G. Semenova} INTELLECTUAL ENERGY SYSTEM // International student scientific bulletin. - 2015. - No. 3-1. URL:

http://www.eduherald.ru/ru/article/view?id=12027 (date accessed: 04/10/2020);

3. Moretti M, Njakou Djomo S, Azadi H, May K, De Vos K, Van Passel S, Witters N. A systematic review of environmental and economic impacts of smart grids. Renew Sustain Energy Rev 2017; 68 (Part 2): 888-98.

4. Labor Code of the Russian Federation of 30.12.2001 N 197-FZ (as amended on 24.04.2020) // ATP "ConsultantPlus";

5. The Constitution of the Russian Federation, taking into account the changes as of $01.08 .2020 / /$ SPS "ConsultantPlus"

6. Code of the Russian Federation on Administrative Offenses of 30.12.2001 N 195-FZ (as amended on 24.04.2020) // ATP "ConsultantPlus";

7. Samantaray, S. 2014. Letter to the Editor: Smart grid initiatives in India. Elect. Power Compon. Syst., 42: 3-4. 262-266;

8. Veselov F.V., Dorofeev V.V. Intelligent energy system of Russia as a new stage in the development of the electric power industry in the digital economy // Digital Energy - 2018. - No. 5. S. 43-52.

9. Zhou, S., Wu, Z., Li, J. and Zhang, X.-P. 2014. Real-time energy control approach for smart home energy management system. Elect. Power Compon. Syst., 42: 3-4. 315-326; 